\title{
Characterization of the Austenite Recrystallization by Comparing Double Deformation and Stress Relaxation Tests
}

S. Vervynckt ${ }^{1}$, K. Verbeken ${ }^{1,2^{*}}$, P. Thibaux ${ }^{3}$ and Y. Houbaert ${ }^{1}$

1. Department of Materials Science and Engineering, Ghent University, Technologiepark 903, B-9052 Ghent, Belgium

2. Max-Planck-Institut für Eisenforschung, Max-Planck-Strasse 1, 40237 Düsseldorf, Germany

3. OCAS N.V., ArcelorMittal R\&D Industry Ghent, J.F. Kennedylaan 3, B-9060 Zelzate, Belgium

* K. Verbeken, Postdoctoral Fellow of the Fund for Scientific Research F.W.O.-Vlaanderen - Belgium

Contact author:

Stephanie Vervynckt

Tel.: 32-9-264-5802

Fax.: 32-9-264-5833

E-mail:Stephanie.Vervynckt@UGent.be

\begin{abstract}
A high amount of deformation below the non-recrystallization temperature $\left(\mathrm{T}_{\mathrm{nr}}\right)$ is a common industrial practice to achieve a good combination of toughness and strength in microalloyed steels. To combine the industrially relevant optimum combination of high productivity and product quality, an accurate knowledge of $T_{n r}$ and the recrystallization kinetics is required. Although a lot of literature data is available on the recrystallization behaviour of microalloyed steels, correlations are often difficult to be made due to the effect of different experimental setups, types of analysis and test schedules that are used to obtain this data. Although this would significantly improve the knowledge about these steels, so far, no systematic comparison has been presented in literature to correlate the different techniques and methods. In this study, different hot rolling simulation techniques, testing schedules and types of analysis were used to determine the recrystallization kinetics of a microalloyed steel. On the one hand, good agreement was found between the results from different test equipment for the double deformations tests. On the other hand, stress relaxation tests showed accelerated kinetics and appeared to be less effective.
\end{abstract}

Keywords: Recrystallization, Double deformation, Stress relaxation, Microalloyed steels 


\section{INTRODUCTION}

Thermomechanical Controlled Processing is a well known way to provide a good combination of strength, fracture toughness and weldability in microalloyed steels. ${ }^{[1]}$ This process is characterized by slab reheating under well defined temperatures, a high amount of hot deformation below the nonrecrystallization temperature $\left(\mathrm{T}_{\mathrm{nr}}\right)$ and accelerated cooling. The non-recrystallization temperature is defined as the temperature below which no complete static recrystallization occurs between the rolling passes. Deformation below $\mathrm{T}_{\mathrm{nr}}$ causes an accumulation of the deformation which results in the formation of elongated grains and deformation bands. Since both grain boundaries and deformation bands act as nucleation sites for the austenite-ferrite transformation and since the austenite grain elongation means that the grain boundaries are getting closer to each other, it is obvious that the deformation below $\mathrm{T}_{\mathrm{nr}}$ increases the nucleation density. In combination with the high nucleation rate caused by the accelerated cooling, the process finally leads to a significant smaller ferrite grain. ${ }^{[2,3]}$ To take advantage of rolling under $\mathrm{T}_{\mathrm{nr}}, 50$ to $80 \%$ of the reduction has to be given below $\mathrm{T}_{\mathrm{nr}}$. If this temperature is low, the roughening plate has to wait until it reaches the right temperature to enter the finishing mill. Waiting, however, means loss of production and money. A better knowledge of $\mathrm{T}_{\mathrm{nr}}$ and more in general of the austenite recrystallization kinetics could optimize the process and the best mechanical properties could be reached at lower cost. Improvement of processes or adaptations of equipment or temperature programs to new products are usually tested under industrial conditions. Such experiments, however, are known to be time and money consuming. Consequently, preliminary tests and analysis on laboratory scale are essential in order to obtain the required knowledge on the hot rolling behaviour of these materials. Different experimental approaches are used in literature for the study and quantification of the recrystallization kinetics: (1) direct observation methods such as optical microscopy $^{[4]}$ and electron backscatter diffraction ${ }^{[5]}$ and (2) external mechanical methods, such as double deformation tests ${ }^{[6-13]}$ and stress relaxation tests, ${ }^{[14-17]}$ which are based on material softening assessment.

Direct measurement of the recrystallized fraction in microalloyed steels is very difficult. The material transforms during cooling and only special etching techniques can be used to reveal former 
austenite grain boundaries (e.g. Béchet-Beaujard ${ }^{[18]}$ ). Moreover, the procedure is tedious and time consuming and in many cases it appears to be impossible to use this technique due to the low hardenability and/or complexities in observing the quenched austenite. Furthermore, it is often difficult to distinguish between the recrystallized and deformed prior austenite grains, consequently the analysis method gives rise to a certain subjectivity. Therefore, mechanical testing techniques such as the double hit test ${ }^{[19]}$ (DHT) and the stress relaxation test ${ }^{[20]}$ (SRT), are mostly preferred. These tests allow to determine the recrystallized fraction as a function of temperature in the time interval after a deformation pass. These isothermal deformation tests can be performed with a great variety of deformation modes on different types of equipment: e.g. torsion on a hot torsion machine, ${ }^{[21,22]}$ uniaxial compression on a plastodilatometer ${ }^{[9,10]}$ or on a high speed press, ${ }^{[7,23]}$ plane strain compression on a Gleeble ${ }^{\circledR[24,25]}$ Furthermore, the non-uniform way to evaluate the softening ratio, i.e. to separate the recovered fraction from the recrystallized fraction, may influence the results obtained from these tests.

Although a large amount of literature data is available on the recrystallization kinetics of microalloyed steels, it is not self-evident to correlate this data one to another since the influence of the deformation schedule, the used equipment and the analysis method, on the resulting recrystallization kinetics remains ambiguous. So far, only few comparisons between different techniques and methods were reported. Iparraguirre et $a .^{[26]}$ studied the differences in recrystallization behavior by double deformation testing using different mechanical testing modes, i.e. uniaxial compression on a dilatometer and torsion tests. Fernandez et al. ${ }^{[21]}$ Andrade et al. ${ }^{[23]}$ and Yanagida et al. ${ }^{[27]}$ described the differences in recrystallization behavior after using different methods to analyze a double deformation test. Other studies ${ }^{[24,25,28,29]}$ discuss the comparison between recrystallized fractions obtained after a double deformation test and after a stress relaxation test. Significant discrepancies can be found between the findings of different authors. However, since these authors used different equipments and analyzing methods to obtain their results, it is extremely difficult to reveal the reason for the observed discrepancy.

The above indicates that, although some specific comparisons between the different methods were reported in literature, a systematic comparison of all the methods for one alloy has not been reported 
yet. The present work aims to determine a relationship between the recrystallization kinetics in the static recrystallization region using different test procedures (double deformation and stress relaxation), combining different types of equipment (hot torsion, plastodilatometry, MTS compression testing) and different analysis techniques for one microalloyed steel. 


\section{EXPERIMENTAL PROCEDURE}

The chemical composition of the microalloyed steel used in this work, can be found in Table 1 . This alloy, a C-Mn-Nb-Mo alloy, contains $0.06 \mathrm{wt} \%$ of $\mathrm{Nb}$ and $0.109 \mathrm{wt} \%$ of Mo and was provided as industrially roughened plate with a thickness of $26 \mathrm{~mm}$. Double deformation tests were performed by torsion on a hot torsion machine and by uniaxial compression on a Bähr ${ }^{\circledR}$ plastodilatometer and on a MTS high speed press. The stress relaxation tests were also performed in torsion on the hot torsion machine and in compression on the Bähr plastodilatometer.

For the torsion tests, specimens were machined from the roughened plate with the specimen long axis parallel to the transverse direction of the plate. The specimens had a gauge length of $25 \mathrm{~mm}$ and a gauge diameter of $6 \mathrm{~mm}$. The torsion tests were performed under argon atmosphere on a computerized torsion machine equipped with an induction heating system and with an 800W Rotero stepper motor, which yields a maximum torque of $7.1 \mathrm{Nm}$ and a maximum revolution speed of $3000 \mathrm{rpm}$. The sample displacement was measured by the number of turns made by the motor, while the temperature was measured by a thermocouple which was welded on one head of the sample near the gauge section.

For the plastodilatometer tests, cylindrical samples with a diameter of $5 \mathrm{~mm}$ and a height of 10 mm were machined by spark-erosion; the axis of the sample being parallel to the normal direction of the plate. The specimens were tested in vacuum under uni-axial conditions using again a Bähr plastodilatometer. The deformation by compression was performed by a hydraulic system with a deformation device which is integrated into the vacuum recipient. For a reduction of friction and also for temperature homogeneity, thin discs of molybdenum were attached to the edges of the samples. In order to be able to perform stress relaxation tests on the plastodilatometer, the valve for smaller oil flow rates was used. This allowed a more accurate control, but also implied that the strain rate before the stroke prior to recrystallization is limited to about $1 / \mathrm{s}$. Immediately after the deformation stroke, the position of the hydraulic piston needed to be fixed with very high precision. In the Bähr dilatometer the position of the piston was measured by a potentiometric system which was connected to the linkage rods near the piston and which transferred the force into the vacuum recipient with the sample. 
For the tests with the high speed press, cylindrical samples with a diameter of $17 \mathrm{~mm}$ and a height of $25 \mathrm{~mm}$ were machined by spark-erosion; the axis of the sample being parallel to the normal direction of the plate. The specimens were tested on a high speed press equipped with an induction coil. The deformation by uniaxial compression was performed by a hydraulic system. The stamps were made of quartz, which has a low heat conductivity to avoid cooling of the edges of the cylindrical sample. For a reduction of friction, thin discs of Sialon were attached to the edges of the samples. Due to friction and impact problems, the deformation rate at these high temperatures was limited to $0.05 / \mathrm{s}$. 


\section{RESULTS AND DISCUSSION}

After a deformation pass, the progress of recrystallization with time can be investigated directly by quenching and subsequent metallographic examination. knowing the recrystallized fraction after a certain interpass time is of great importance for the degree of deformation that can be accumulated during the next deformation pass. The greater this accumulation, the finer the final ferrite grains will be. However, as mentioned above, in many cases it appears to be impossible to use metallography due to a low hardenability and/or complexities in observing the quenched austenite. Therefore, two mechanical testing procedures, the double deformation technique and the stress relaxation technique are preferred. Section 3.1 describes the use of double deformation tests. The recrystallization kinetics obtained after using different analysis techniques and using different equipment types (hot torsion, plastodilatometry and MTS compression testing) were determined and compared. In section 3.2, the recrystallization kinetics obtained after stress relaxation testing are discussed. The existing analysis techniques are reviewed and the resulting kinetics after using different test equipment (torsion and plastodilatometry) are compared. Finally, in section 3.3 a comparison is made between results from the double deformation and the stress relaxation tests.

\subsection{DOUBLE DEFORMATION TESTING}

In a double deformation test, the recrystallization kinetics can be indirectly monitored by the degree of softening measured from an interrupted mechanical test. The principle of such a double deformation technique is illustrated in Figure 1. After a reheating cycle and subsequent cooling to a specific deformation temperature, a first deformation pass is given. After this deformation, the stress is immediately relieved to a minimum value necessary to keep the sample in position. After variable waiting times (interpass times, $\mathrm{t}_{\mathrm{ip}}$ ), a second deformation pass with the same strain and strain rate as the first deformation pass is applied. The softening fraction is determined by comparing the stressstrain curves for both deformation passes. The shape of the second deformation curve is strongly influenced by the time between the two deformation passes. If the interpass time is sufficiently high 
for full softening to occur, the second flow curve should be identical to the first flow curve. If there is no softening at all, the second flow curve should appear as an extrapolation of the first flow curve.

In literature, various analyzing methods, i.e. back extrapolation method, mean flow stress method, offset methods,... have been used to calculate the fraction of softening from the stress-strain curves resulting from a double deformation test. Moreover different simulation equipment, i.e. hot torsion machine, plastodilatometer, high speed press, gleeble,.. have been used in these studies to perform these interrupted mechanical tests. ${ }^{[6-13]}$ The different ways of analysis and the various types of equipment make it very difficult to correlate the data one to another. Therefore, the influence of the analyzing method and the used equipment on the resulting recrystallization kinetics are evaluated in this work.

\section{A. Influence of the analyzing technique on the recrystallized fraction}

The most frequently used techniques for analyzing stress-strain curves from a double deformation test in order to calculate the recrystallized fraction are the $0.2 \%$ and $2 \%$ offset-methods, the 5\% true strain method, the back extrapolation method and the mean flow stress method. Details and practical aspects about these methods were discussed by Fernandez et al. ${ }^{[21]}$.

After calculation of the softening fraction resulting from a double deformation test, a rich variety in behaviour has been observed when this softening fraction was plotted versus time. This behaviour can be roughly grouped into three categories: (i) monotonically increasing softening curves, (ii) softening curves with a single plateau and (iii) softening curves with two plateaus. In almost all studies $^{[22,24,30-32]}$ the degree of softening, calculated from the curves is directly related to the recrystallized fraction. This means that also the recrystallization versus time curves show the three main shapes mentioned above. Although this recrystallization behaviour is frequently found, there exists no standard calculation method in literature. Some authors assume that the $0.2 \%$ offset method displays a linear relation with the statically recrystallized volume fraction ${ }^{[6]}$, while other authors argue in favour of the $2 \%$ offset method ${ }^{[7]}$, the back extrapolation method ${ }^{[8-10]}$ or the mean flow stress method $^{[11-13]}$ to determine this fraction. 
Figure 2 shows the variation of the softening fractions determined by the different analyzing methods as a function of the interpass time, for the C-Mn-Nb-Mo alloy deformed with a plastodilatometer at $1000^{\circ} \mathrm{C}$. The curves follow an Avrami type equation of the shape shown in Eq. 1, in which $\mathrm{X}$ is the recrystallized fraction, $\mathrm{t}$ the time, $\mathrm{t}_{0.5}$ the time for $50 \%$ of recrystallization and $\mathrm{n}$ the Avrami exponent, typically between 1 and 2 :

$$
X=1-\exp \left(-0.693 \cdot\left(\frac{t}{t_{0.5}}\right)^{n}\right)
$$

Although for all methods, the recrystallized fraction is obviously found to increase with time, some important differences exist between them. From Figure 2 it is clear that the $t_{0.5}$ and the Avrami exponent are different for all methods; only the $2 \%$ offset method and the $5 \%$ true strain method seem to provide similar results over the whole range of interpass times. With the $0.2 \%$ offset method, the highest recrystallized fractions are found for all interpass-times and recrystallization is completed in 50s. Similar results were reported by Fernandez et al. ${ }^{[21]}$ The other methods, i.e. $2 \%$ offset, $5 \%$ true strain, back extrapolation and mean flow stress method, show similar times of about 200s to reach complete recrystallization. However, for shorter interpass times some differences can be noticed in the recrystallized fraction obtained with these methods. While the fractions determined with the $2 \%$ offset method and with the 5\% true strain method are rather similar over the whole time interval as indicated above, the mean flow stress method gives recrystallized fractions which are about $10 \%$ higher at the shorter interpass times. After higher interpass times the difference with the $2 \%$ offset method becomes smaller or even disappears. The opposite is true for the back extrapolation method, similar fractions as the $2 \%$ offset method are found at short interpass times while $10 \%$ lower fractions are seen at longer interpass times of 50 and 200s. Similar differences between the $2 \%$ offset method and the back extrapolation method were reported by other authors. ${ }^{[21,23]}$

A possible explanation for these differences can be found in the fact that both recovery and recrystallization occur during interpass softening. Consequently, the separation of these processes and the sole influence of recrystallization on the flow stress curve of the second pass may be difficult to distinguish accurately. Therefore, different analyzing methods include variable amounts of recovery in 
the softening data. Since recovery affects the early stage of work hardening, it appears that the $0.2 \%$ offset method includes a significant amount of softening due to recovery before the onset of recrystallization. Apparently also some recovery effects, though to a smaller extent, are included in the mean flow stress method so that in this case as well the recrystallized fraction is overestimated. Another disadvantage of the $0.2 \%$ offset method is that it is often very difficult to accurately determine the $0.2 \%$ offset stress, which implies a higher degree of uncertainty in the recrystallization curves.

The 5\% true strain method is based on the idea that after a strain of 5\% the flow stress of the reloading pass is restored to the level of the flow stress of continuous deformation. The key to quantifying the degree of recrystallization seems to be the use of a large enough strain, i.e. 5\%. This method has the advantage that it actually measures the recrystallized fraction without recovery, as was proven by Perttula et al. ${ }^{[25]}$ who successfully compared the $5 \%$ true strain fractions with metallographic measurements. However, this method also has some disadvantages. First of all, the stress of the work hardened material is needed but the extrapolation to obtain this value is not always straightforward and second, the larger the strain used for the analysis, the lower the sensibility of the measurement. At larger strains the stress values of the second deformation curves for different interpass times are closer to each other. Since in Figure 2 the recrystallized fractions determined with the $5 \%$ true strain method are exactly the same as those determined with the $2 \%$ offset method, it is assumed that the $2 \%$ offset method minimizes the effect of recovery as well. Furthermore, the $2 \%$ offset method has a greater sensibility, i.e. the stress is measured at lower strains, and does not require the often doubtful extrapolation of the first deformation curve. For this reason, the $2 \%$ offset method is chosen for the analysis of the double deformation curves in the next section. Although several authors ${ }^{[8-10]}$ favour the back extrapolation method, in the present work chose the $2 \%$ offset method is chosen because that the back extrapolation method uses the $0.2 \%$ offset stress of the first deformation curve, which is difficult to determine, as was mentioned above. Further, the extrapolation analysis itself is also not straightforward. As a consequence, the difficulty of the analysis can lead to lower fractions as is shown in Figure 2. 


\section{B. Influence of the testing equipment on the recrystallized fraction}

Another aspect that makes it difficult to correlate recrystallization data from several sources, is the fact that most authors use their own hot deformation simulation equipment. The most frequently used types of equipment are hot torsion, ${ }^{[21,22]}$ Gleeble, ${ }^{[24,25]}$ servohydraulic uniaxial compression testing ${ }^{[7,23]}$ and plastodilatometry. ${ }^{[9,10]}$ To the authors knowledge, very few data is available on the comparison of the recrystallized fraction obtained from different simulation techniques. Only Iparraguirre et al. ${ }^{[26]}$ compared softening fractions obtained from plastodilatometry and from torsion, showing a difference in softening level between both types of tests. In spite of these differences, they found a relatively good correlation in the measurements of the precipitate size and the amount of $\mathrm{Nb}$ precipitated in the different types of experiments.

In this work, three different simulation techniques were used to study the recrystallized fraction of the C-Mn-Nb-Mo alloy deformed at $1000^{\circ} \mathrm{C}$ : (1) MTS servohydraulic uniaxial compression testing, (2) plastodilatometry and (3) hot torsion testing. Details on sample geometry and test setup were presented in section 2. The stress-strain curves of the double deformation tests are presented in Figure 3. Figure 3(a) and (b) show the results obtained with a high speed press and a plastodilatometer, respectively. In both of the cases, the stress and the strain are derived from a uniaxial force parallel to the axis of the cylindrical sample and a reduction of the cylinder height ${ }^{[33]}$ :

$$
\begin{aligned}
& \varepsilon=\ln \left(\frac{h}{h_{0}}\right) \\
& \sigma=\frac{4 \cdot P \cdot h}{\pi \cdot D_{0}^{2} \cdot h_{0}}
\end{aligned}
$$

In these formula $\mathrm{h}$ is the instantaneous height of the sample during deformation, $\mathrm{h}_{0}$ the initial height of the sample before deformation, $\mathrm{D}_{0}$ the initial diameter and $\mathrm{P}$ the uniaxial force in the absence of friction. In order to correct for the friction or barrelling effect, Siebel ${ }^{[34]}$ proposed the following relationship for the stress:

$$
\bar{\sigma}=\left(1+\frac{2 \cdot \mu \cdot D}{3 \cdot h}\right) \cdot \sigma
$$


In which $\bar{\sigma}$ is the corrected uniaxial stress and $\mu$ the friction coefficient due to friction between the anvils and the sample.

Figure 3(c) shows the results obtained from hot torsion, in which the stress and the strain are derived from a certain torque $\mathrm{T}$ and a twist $\theta$ of the sample around its longitudinal axis respectively ${ }^{[35]}$ :

$$
\begin{aligned}
& \sigma=\frac{3.3 \cdot \sqrt{3} \cdot T}{2 \cdot \pi \cdot R^{3}} \\
& \varepsilon=\frac{\theta \cdot R}{\sqrt{3} \cdot L}
\end{aligned}
$$

where $\mathrm{R}$ and $\mathrm{L}$ are the gauge radius and gauge length of the hot torsion samples, respectively. It is clear that in torsion, Figure 3(c), a much larger area of elastic deformation is found in comparison with the stress-strain curves obtained from uniaxial compression, Figure 3(a) and (b). This is caused by the stiffness of the system: the angle of twist is measured far from the gauge section. Furthermore, in torsion, the heads of the machine are in contact with the sample during the complete test. This results in speed-up problems when the strain rate has to increase from 0 to its actual value during deformation. Consequently, in the first part of the deformation curve in torsion the strain rate is not constant which makes it difficult to accurately determine the yield stress. Furthermore, in torsion, during the interpass-time the sample stays fixed between the heads, so complete unloading is difficult to achieve. In Figure 3(c) this is seen by the fact that between the deformation passes an offset stress value of at least $7 \mathrm{MPa}$ (for the longer interpass-times) remains. Uniaxial compression, i.e. deformation with a high speed press and a plastodilatometer, does not display these speed up problems nor the unloading problems since the compression anvil is not in contact with the sample before deformation or between both deformation steps. The fact that this anvil is not in contact with the sample has also several disadvantages. At first, when the 'cold' anvil hits the sample to start the deformation, it is possible that the temperature of the sample drops due to this contact and second, when the anvil hits the sample, fracture of the anvil is not unthinkable. Therefore, a rather complex setup (quartz, Mo-plates,..) for these type of equipments is needed, definitely when higher strain rates are applied. Since each equipment has its own practical problems to perform hot deformation tests, it would be interesting to know the correspondence between the resulting recrystallized fractions. 
The recrystallized fractions are presented in Figure 4. It is immediately clear that there is a very good agreement between the recrystallized fraction obtained by plastodilatometry (circles) and that by MTS (squares). From both tests, which were performed with exactly the same strain, i.e. 0.3 and strain rate, i.e. $0.05 / \mathrm{s}$, one can conclude that recrystallization starts about one second after the deformation and is nearly $100 \%$ completed in 100s. When the fractions from plastodilatometry (circles) are compared with those from the hot torsion test (filled triangles), one peculiarity arises, namely, the dilatometer tests were performed with a strain rate of $0.05 / \mathrm{s}$ and a strain of 0.3 while the torsion tests were performed with a strain rate of $1 / \mathrm{s}$ and a strain of 0.3 . Moreover, in hot torsion this strain and strain rate were calculated at the outer surface, i.e. $\mathrm{R}=3 \mathrm{~mm}$ in Eq. 6 . Since it is well known that strain and strain rate vary from 0 , in the middle, to maximum, at the outer surface, the recrystallized fraction will also vary over the sample diameter. To be able to visualize this variation, local recrystallized fractions were calculated, based on the Avrami equation (Eq. 1) in which the time for 50\% recrystallization, $\mathrm{t}_{0.5}$, is often expressed as:

$$
t_{0.5}=A \cdot \varepsilon^{p} \cdot \dot{\varepsilon}^{q} \cdot D_{0}^{s} \cdot \exp \left(\frac{Q_{r e x}}{R T}\right)
$$

In which $\varepsilon$ is the strain, $\dot{\varepsilon}$ the strain rate, $\mathrm{D}_{0}$ the original austenitic grain size, $\mathrm{Q}_{\text {rex }}$ the activation energy for recrystallization, $\mathrm{A}, \mathrm{p}, \mathrm{q}$ and $\mathrm{s}$ are constants and $\mathrm{R}$ is the universal gas constant. The values of these parameters can be found elsewhere. ${ }^{[37]}$ In that way the $t_{0.5}$ for a local strain ' $b$ ' and local strain rate ' $\dot{b}$ ' can be calculated directly when the $t_{0.5}$ determined from tests performed with a strain ' $a$ ' and strain rate ' $\dot{a}$ ' is known.

$$
t_{0.5}(b, \dot{b})=t_{0.5}(a, \dot{a}) \cdot\left(\frac{b}{a}\right)^{p} \cdot\left(\frac{\dot{b}}{\dot{a}}\right)^{q}
$$

In the present case, the $t_{0.5}(\mathrm{a}, \dot{\mathrm{a}})$ is the time for $50 \%$ of recrystallization as determined experimentally from the hot torsion tests performed with a strain of 0.3 and a strain rate of $1 / \mathrm{s}$, both measured at the surface. The strain $b$ varies from 0 , in the middle, to 0.3 , at the surface and the strain rate ' $\dot{b}$ ' varies analogously from 0 to 0.05 , see Figure 5(a). This strain rate of 0.05 at the surface was chosen to have an equal strain rate as in the uniaxial compression tests. 
The calculated $t_{0.5}(\mathrm{~b}, \dot{\mathrm{b}})$ values were imported into Eq. 1 and consequently local values for the recrystallized fractions were obtained and plotted in Figure 5(b). It can be seen that for short interpass times, the variation of the recrystallized fraction over the diameter is rather small. However, for longer interpass times, i.e. 20 and 100s, there is a variation from $0 \%$ recrystallization in the middle of the sample to 70 and $100 \%$ at the surface, respectively. These results are in agreement with the results of Choquet et al. ${ }^{[38]}$ who observed a non-recrystallized core that extended up to $2 \mathrm{~mm}$, around which a recrystallized ring, i.e. a tube with an inner diameter of $2 \mathrm{~mm}$ and an outer diameter of $3 \mathrm{~mm}$, was present. The average recrystallized fractions over the recrystallized ring are plotted as open triangles in Figure 4 and correspond well to the recrystallized fractions obtained from uniaxial compression. Thus if the recrystallized fractions resulting from uniaxial compression tests are compared to the average recrystallized fractions in the outer ring of hot torsion samples, similar fractions are found for the complete time interval. Even if only the fractions at the outer surface are considered, i.e. the top of the error bars in Figure 4, relatively good agreement with the uniaxial compression experiments is found. This is an important result since most authors ${ }^{[21,22,26]}$, so far, have calculated the recrystallized fractions from hot torsion tests taking into account only the deformation conditions at the surface. Moreover, it should also be noticed that the applied deformation mode will have an influence on the crystallographic texture development, which on his turn might affect the recrystallization process. This was for example demonstrated by Zhu et al. ${ }^{[39,40]}$, who identified some important effects of variations in the deformation texture on the recrystallization kinetics in Aluminum alloys. A detailed investigation of this feature was, however, out of the scope of this work.

A drawback of double deformation tests in general is, however, the high amount of tests necessary. A possible way of limiting the number of tests but still achieving the full recrystallization versus time curve, is to perform stress relaxation tests. These tests, as well as a comparison with the results from the double deformation tests, are described in the next section.

\subsection{STRESS RELAXATION TESTING}


Although double deformation tests are proven to be an important tool for the determination of the evolution of the recrystallized fraction with time, the technique has two important disadvantages. At first, the contributions of recovery and recrystallization cannot explicitly be separated. Secondly, the double deformation procedures are tedious because for each point a new sample is needed and a complete program of thermomechanical treatment has to be performed. The method of stress relaxation, however, allows measuring the total course of the softening behavior in only one sample. Furthermore, stress relaxation enables the determination of both recovery and recrystallization kinetics of austenite after deformation. In spite of these huge advantages over the double deformation technique, stress relaxation testing is much less used when studying the recrystallization kinetics. On the one hand, there are a lot of practical problems in a stress relaxation test such as homogeneity of deformation, ageing and work hardening during stress relaxation, temperature sensitivity of the equipment and also relaxation of the equipment. ${ }^{[41]}$ On the other hand, the analysis of a stress relaxation curve is not always straightforward. Below, these problems are described more in detail by using different types of equipment types to perform a stress relaxation test under similar experimental conditions. Furthermore, to validate the results of a stress relaxation test, the obtained recrystallized fractions for the C-Mn-Nb-Mo alloy are compared with those from a double deformation test, obtained under exactly the same experimental conditions.

\section{A. Principle and analysis of a stress relaxation test}

The principle of a stress relaxation test is shown in Figure 6. After a reheating cycle and subsequent cooling to deformation temperature, the sample was deformed. After deformation, the sample was kept in a fixed position, i.e. holding the sample without displacement of the anvils, during a certain time period (without relieving the stress). During that period the change in stress was recorded and stress relaxation occurred as a result of softening. This appears on a stress versus log time curve as a typical sigmoidal shape. Karjalainen ${ }^{[42]}$ assumes that static recovery and recrystallization do not occur at the same time and proposes a technique that permits the separation of both processes. According to his procedure, the stress relaxation curve of a recrystallizing material shows three distinct regions (see Figure 6): (1) a straight line with a slow decrease, (2) a rapid decrease 
and (3) a second straight line with a slow decrease or constant stress level. The first linear stage of relaxation corresponds to the stress relaxation in the strained austenite by creep and recovery, while the third stage, where the slope is smaller and sometimes zero, corresponds to the stress relaxation of the soft austenite by creep and/or grain growth. The rapid decrease in the second stage originates from the softening of the work hardened austenite, which is mainly due to static recrystallization. If it is assumed that a partially recrystallized material consists of two phases (work hardened and fully softened), and an equi-strain mixture rule is applied, the stress level in the softening stage can then be expressed in terms of the relative fractions of these phases. Hence, the stress at a given time $t$ is:

$$
\sigma=(1-X) \cdot\left(\sigma_{1}-\alpha_{1} \cdot \log (t)\right)+X \cdot\left(\sigma_{2}-\alpha_{2} \cdot \log (t)\right)
$$

Where $\mathrm{X}$ is the fraction of recrystallized material. From this equation it can be derived that:

$$
X=\frac{\sigma_{1}-\alpha_{1} \cdot \log (t)-\sigma}{\left(\sigma_{1}-\sigma_{2}\right)-\left(\alpha_{1}-\alpha_{2}\right) \cdot \log (t)}
$$

When $\mathrm{X}(\mathrm{t})$ is plotted as a function of time, see Figure 6, the typical sigmoidal recrystallization curve is obtained, which can subsequently be fitted to a recrystallization model such as for example an Avrami type of model. The described procedure is found to give satisfactory results for C-Mn steels ${ }^{[14,15]}$ and microalloyed steels deformed above the solubility temperature of the precipitates

present. ${ }^{[16,17]}$ Practical problems arise when it is not possible to determine the reference curve B. This is the case when the relaxation time is too short, or alternatively when the recrystallization is too slow due to the appearance of strain induced precipitates that exert a pinning force on the recrystallizing grain boundaries. In those situations, it will be impossible to determine the recrystallized fractions versus time. Therefore, the stress relaxation tests performed on microalloyed steels in this work are limited to deformation temperatures above the solubility temperature of the NbC-precipitates.

\section{B. Influence of the measuring technique on the recrystallized fraction}

In Figure 7 , the results from two stress relaxation tests at $1000^{\circ} \mathrm{C}$ on the $\mathrm{C}-\mathrm{Mn}-\mathrm{Nb}-\mathrm{Mo}$ industrial alloy, are presented. In Figure 7(a) the test is performed with a torsion machine while in Figure 7(b) the test is performed with a plastodilatometer in deformation mode. From the relaxation in torsion mode, it is observed that the relaxation curve starts to deviate form the linear curve ' $A$ ' after 
approximately $0.09 \mathrm{~s}$, indicating a recrystallization start time $\mathrm{X}_{\mathrm{s}}$ of $0.08 \mathrm{~s}$. In the same way, the recrystallization finish time, $X_{f}$ is found to be nearly 40s. Similarly $X_{s}$ and $X_{f}$ determined from a dilatometer test are $0.7 \mathrm{~s}$ and just above 50s, respectively, see Figure 7(b). It is concluded that, except for the recrystallization finish time, both curves show some important differences. The recrystallization appears to start significantly faster in the torsion test and moreover, the complete shape of the relaxation curves is very different. Where the relaxation curve in torsion is rather smooth, the relaxation curve obtained from a plastodilatometer shows some fluctuations. The most important fluctuation of about $6 \mathrm{MPa}$ is found after $5 \mathrm{~s}$ of relaxation. Similar fluctuations were found by Engberg and Lisse ${ }^{[43]}$ and were pointed out by Karjalainen et al. ${ }^{[44]}$ as machine characteristics. Indeed, during relaxation in a plastodilatometer, the height of the cylindrical specimen $\mathrm{h}$ must be kept a constant, because a constant total strain is needed. This condition is equivalent to maintaining the mobile part of the machine into a fixed position after compression. However, if the compression column does not present an infinite stiffness, the relaxation of the whole setup, i.e. specimen and compression column, is recorded.

During relaxation, a decrease of the stress by $\Delta \sigma$ causes a decrease of the applied force of $\Delta \mathrm{F}$ and the deformation of the column is released by $\Delta \delta=\Delta \mathrm{F} / \mathrm{k}$ where $\mathrm{k}$ is the spring constant (or stiffness) of the equipment. In order to keep h constant, the gap between the tools should increase by $\Delta \delta$. Moreover, any fluctuation $\Delta \mathrm{h}$ of the position of the anvils would result into an elastic variation in the stress in the specimen of:

$$
\Delta \sigma=E \cdot \frac{\Delta h}{h}
$$

Where $\mathrm{E}$ is the Young modulus of the specimen. For steels, this means that a variation of $\Delta \mathrm{h}=1 \mu \mathrm{m}$ results in $\Delta \sigma=10 \mathrm{MPa}$ for a specimen height of $10 \mathrm{~mm}$ after deformation, proving that the change must have been about $0.6 \mu \mathrm{m}$ to obtain a fluctuation in stress of $6 \mathrm{MPa}$. Similarly, any fluctuation in the temperature of the specimen will cause a thermal dilatation (or contraction) of the specimen and a resultant increase (or decrease) in the stress:

$$
\Delta \sigma=E \cdot \alpha \cdot \Delta T
$$


Where $\alpha$ is the thermal expansion coefficient of the specimen, typically $2.10^{-5} \mathrm{~K}^{-1}$ for low carbon austenite. A temperature difference of $5^{\circ} \mathrm{C}$ during relaxation thus results in $\Delta \sigma=10 \mathrm{MPa}$. The previous illustrates that an accurate control of both the mechanical position of the anvils and the temperature during high temperature stress relaxation is essential to obtain reliable results.

The question can now be put forward whether the smooth relaxation curves obtained from a torsion test, cf. Figure 7(a), are really trustworthy. Anvil nor temperature fluctuations seem to influence the shape of curve and furthermore it is difficult to believe that recrystallization starts only $0.08 \mathrm{~s}$ after deformation. Therefore, the recrystallized fraction obtained from relaxation tests in hot torsion are compared to recrystallized fractions obtained from double deformation tests.

\subsection{COMPARISON BETWEEN STRESS RELAXATION TESTING AND DOUBLE DEFORMATION TESTING}

Three stress relaxation tests at different deformation temperatures were performed in torsion mode. The resulting relaxation curves are presented in Figure 8 . For the relaxation curve at $900^{\circ} \mathrm{C}$, at the end of the test, the stress value was still decreasing, making this test not suitable to use for analysis following the Karjalainen approach. For the other temperatures, i.e. $1000^{\circ} \mathrm{C}$ and $1050^{\circ} \mathrm{C}$, the recrystallized fractions vs. time were calculated and plotted against the results from the double deformation tests, also performed in torsion with exactly the same strain and strain rate. The results are showed in Figure 9 and demonstrate a significant discrepancy between the two types of tests. For both temperatures the kinetics seem to be strongly accelerated when a stress relaxation test is applied. Although Karjalainen et al. ${ }^{[24,25]}$ found a very good agreement between recrystallized fractions obtained from double deformation and from stress relaxation, these accelerated kinetics in stress relaxation were reported also by other authors. ${ }^{[28,29,45,46]}$ Several reasons are found to explain this acceleration. At first, the stress present during the stress relaxation (sample stays loaded) not only accelerates recovery by assisting the dislocation climb but can also accelerate the recrystallization kinetics. A second reason could be that the constant level reached after long relaxation times does not represent a completely softened structure, but a structure where the driving force for further softening is lower than a critical driving force, which is temperature dependent, to still have further softening. 
Finally, a third reason could lie in the fact that the total stress after deformation consists of a viscous part and a part due to the deformation. It is of course so that the viscous stress $\sigma_{v}$, which depends on temperature and strain rate is close to 0 during a relaxation test, while it is different from 0 during deformation. So a part of the drop in stress during a stress relaxation test could be due to a drop in viscous stress and does not represent a softening phenomenon in the material. ${ }^{[47,48]}$ For the stress relaxation tests in hot torsion, the third reason seems to be acceptable. Taking into account this viscosity effect, the relaxation curve of Figure 7(a) could be divided in three new regions which are different from the three regions of the Karjalainen approach. These three new regions are: 1) a fast and abrupt decrease of the stress, due to a viscous relaxation of the effective stress, until a static stress value, $\sigma_{\text {stat }}$, is reached 2) a decrease of the stress generally attributed to the progress of static recrystallization in the material. 3) a stationary regime corresponding to an internal stress in the fully recrystallized material, similar to curve 'B' of the Karjalainen approach. Indeed, this $\sigma_{\text {stat }}$ value is reached after $0.7 \mathrm{~s}$ implying a true recrystallization start at $0.7 \mathrm{~s}$ after the deformation. This recrystallization start time corresponds very well with the recrystallization start time found after relaxation with a plastodilatometer, as mentioned above.

The previous results indicate that although stress relaxation tests have a great potential for analyzing the recrystallization behaviour of microalloyed steels, some important issues remain. Firstly, very accurate machine and temperature control is needed but in practice they are not always easy to obtain and secondly, depending on the equipment used for the stress relaxation test, a different analyzing method is needed mainly due to differences in the viscous relaxation of the material.

\section{CONCLUSIONS}

In this work a systematic comparison between the recrystallization kinetics in the static recrystallization region using double deformation and stress relaxation tests, combining different types of testing equipment (hot torsion, plastodilatometry, MTS compression testing) is made. The results can be summarized as follows:

- Between the six analyzing methods considered to analyse the fractional softening obtained from double deformation tests, there are two which exclude better the effect of recovery and are thus 
more suitable to describe the static recrystallization kinetics of microalloyed steels: the $5 \%$ true strain method and the $2 \%$ offset method. The latter was proposed as being the most accurate and reliable one. Although the method that is used for analyzing double deformation curves influences the recrystallization, double deformation tests are found to be very useful for comparison between different authors. It is shown in this work that the type of testing equipment does not have an influence on the calculated recrystallized fractions.

- Stress relaxation tests are found to be less effective in determining the recrystallization behavior of microalloyed steels. First of all, a very difficult and precise setup and control of the temperature and the deformation system is necessary. This leads to a big difference in recrystallization kinetics when the same test is performed with a different type of equipment. Further, there exists no standard method for analyzing relaxation curves that can be used for all types of equipment, at all testing temperatures. Finally, the resulting recrystallization kinetics cannot be compared with results from double deformation. In this work, accelerated kinetics were found when the stress relaxation method was used. 


\section{REFERENCES}

[1] T. Gladman: The Physical Metallurgy of Microalloyed Steels, The Institute of Materials, The University Press, London, 1997.

[2] R. Abad, B. Lopez and I. Gutierrez, Mater. Sci. Forum, 284-286 (1998), 167.

[3] A. Kojima, Y. Watanabe, Y. Terada, A. Yoshie and H. Tamehiro, ISIJ int., 36 (1996), No. 5, 603.

[4] M. Gomez, L. Rancel, B.J. Fernandez, S.F. Medina: Mater. Sci. Eng. A, 501 (2009), 188.

[5] L. Bracke, K Verbeken, L. Kestens, J. Penning: Acta Mater., 57 (2009), 1512.

[6] Y. Xu, Y. Cui and H. Shong: Proc. of the 39th MWSP Conference on ISS, ed. the Iron and Steel Society, Indianapolis, IN, 1997, p. 641.

[7] G. Li, T. M. Maccagno, D. Q. Bai, J. J. Jonas: ISIJ Int., 36 (1996), 1479.

[8] P. Choquet, A. Le Bon, Ch. Perdrix: Strength of Metals and Alloys, ed. H. J. Mcqueen et al., vol. 3, Pergamon Press, Oxford, 1986, p. 1025.

[9] C. Devadas, I. V. Samarasekera, E. B. Hawbolt: Metall. Mater. Trans. A, 22A (1991), 335.

[10] W. Bleck, C. Herzig, M. Venkatraman: Steel Res., 74 (2003), 311.

[11] E. J. Palmiere, C. I. Garcia, A. J. De Ardo: Metall. Mater. Trans. A, 27A (1996), 951.

[12] A. Laasraoui, J. J. Jonas: Metall. Mater. Trans. A, 22A (1991), 151.

[13] O. Kwon, A. J. De Ardo: Acta Metall. Mater., 38 (1990), 41.

[14] A. Smith, A. Miroux, J. Sietsma, S. van der Zwaag: Steel Res., 77 (2006), 595.

[15] H. Luo, J. Sietsma, S. van der Zwaag: Metall. Mater. Trans. A, 35A (2004), 1889.

[16] Z. Zhang, X. Liang, Y. Liu: Mater. Sci. Forum, 544-545 (2007), 47.

[17] W.J. Liu, J.J. Jonas: Metall. Trans. A, 19A (1988), 1403.

[18] S. Bechet, L. Beaujard: Rev. Metall., 52 (1955), 830.

[19] C.M. Sellars: Proc. Int. Conf. on Hot Working and Forming Processes, Sheffield, UK, July 3-15, 1979.

[20] K. Okazaki, Y. Aono: Z. Metallkd., 68 (1977), 368.

[21] A.I. Fernandez, B. Lopez, J.M. Rodriguez-Ibabe: Scr. Mater., 40 (1999), 543. 


\section{(1998), 119.}

[25] J.S. Perttula, L.J. Karjalainen, Mater. Sci. Technol., 14 (1998), 626.

[26] I. Parraguirre, A. I. Fernández, B. López, C. Scott, A. Rose, W. Kranendonk, B. Soenen, G. Paul: Mater. Sci. Forum, 500-501 (2005), 677.

Final report of the ECSC Steel RTD Programme: 'New Concepts for understanding and modeling the influence of austenite state on phase transformations in hot rolled steels', Maizières-lès-Metz, France, 2003.

[30] K. B. Kang, O. Kwon, W. B. Lee, C. G. Park: Scr. Mater., 36 (1997), 1303.

[31] S. F. Medina, A. Quispe: Steel Res., 67 (1996), 257.

[32] S. F. Medina, A. Quispe: Mater. Sci. Forum, 426-432 (2003), 1139.

[33] B. Roebuck, J.D. Lord, R.K. Varma, M.S. Loveday: Measuring Flow Stress in Hot Axisymmetric Compression Tests, Measurement Good Practice Guide, No. 3, Issue 2, 2002.

[34] E. Siebel: Stahl Eisen, 43 (1923), 1295.

[35] A. Gräber and K. Pöhlandt: Steel Res., 61 (1990), 212.

[36] D.Q. Bai, S. Yue, W.P. Sun, J.J. Jonas: Metall. Mater. Trans. A, 24A (1993), 2151.

[37] A.I. Fernandez, P. Uranga, B. Lopez, J.M. Rodriguez-Ibabe, ISIJ Int., 40 (2000), 893.

[38] P. Choquet, A. Le Bon, C. Rossard, C. Perdrix, G. Joannes: Int. Conf. On Physical Metallurgy of Thermomechanical Processing of Steels and Other Metals, Thermec '88, Vol. 2, Tokyo, Japan, 6-10 June, 1988, 729.

[39] Q. Zhu, C. M. Sellars, Aluminum alloys 2002, Their physical and mechanical properties, Mater. Sci. Forum, 394-396 (2002), 487. 
[40] Q. Zhu, B. P. Wynne, J. H. Beynon, C. M. Sellars, Texture of materials, Mater. Sci. Forum, 404-408 (2002), 1489.

[41] K. Okazaki, M. Kagawa, Y. Aono: Z. Metallkd., 67 (1976), 47.

[42] L. P. Karjalainen: Mater. Sci. Technol., 11 (1995), 557.

[43] G. Engberg, L. Lissel: Steel Res.,79 (2008), 47.

[44] L.P. Karjalainen, J. Perttula, Y. Xu, J. Niu: Proc. 7th Int. Symp. on Physical Simulation of Casting, Hot Rolling and Welding, Tsukuba; Japan, 1997, p. 231-36.

[45] L. Vasquez, H.J. Mcqueen: Acta Metall., 35 (1987), No. 8, 1951.

[46] P.J. Wray: Metall. Mater.Trans. A, 6A (1975), 1197.

[47] S. Vervynckt, P. Thibaux, B. Soenen, Y. Houbaert: Proc. of the international symposium on advanced steels, Montreal, Canada, 2006.

[48] Z. Gronostajski: J. Mater. Proc. Technol., 157-158 (2004), 165. 


\section{FIGURES CAPTIONS}

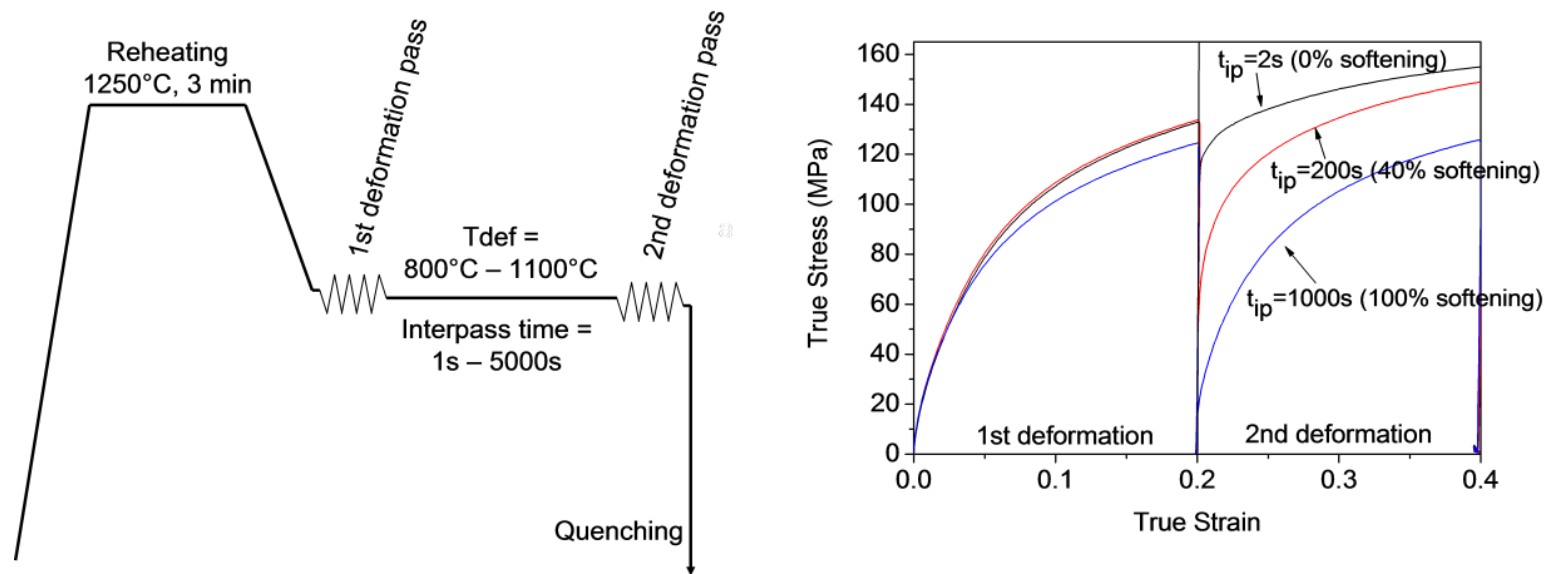

Figure 1. Principle of the double deformation test (left), resulting stress-strain curves from the double deformation test used to calculate the fraction of softening during the interpass time (right).

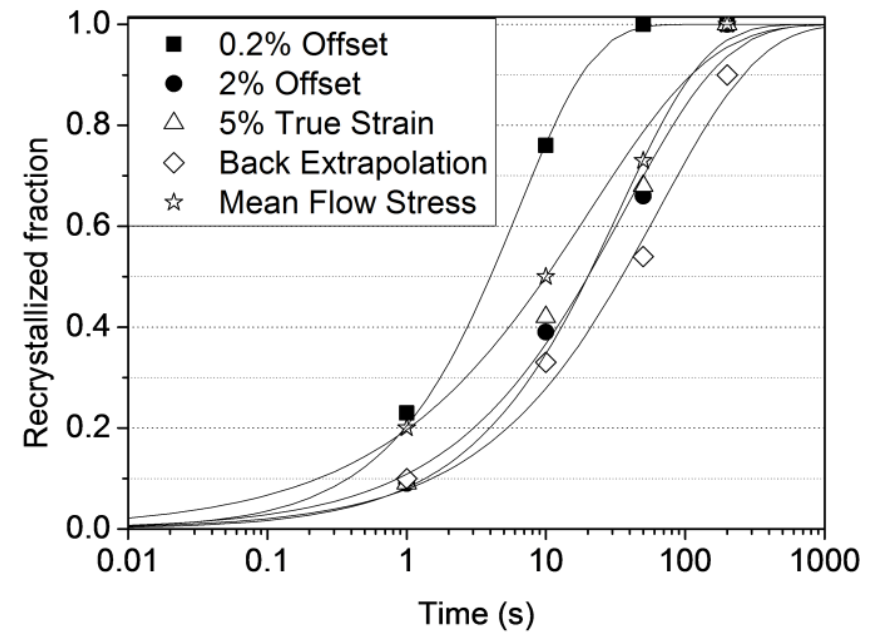

Figure 2. Comparison between the different analyzing methods for calculating the recrystallized fraction from a double deformation test on the Nb-Mo alloy deformed with the dilatometer at $1000^{\circ} \mathrm{C}$. 

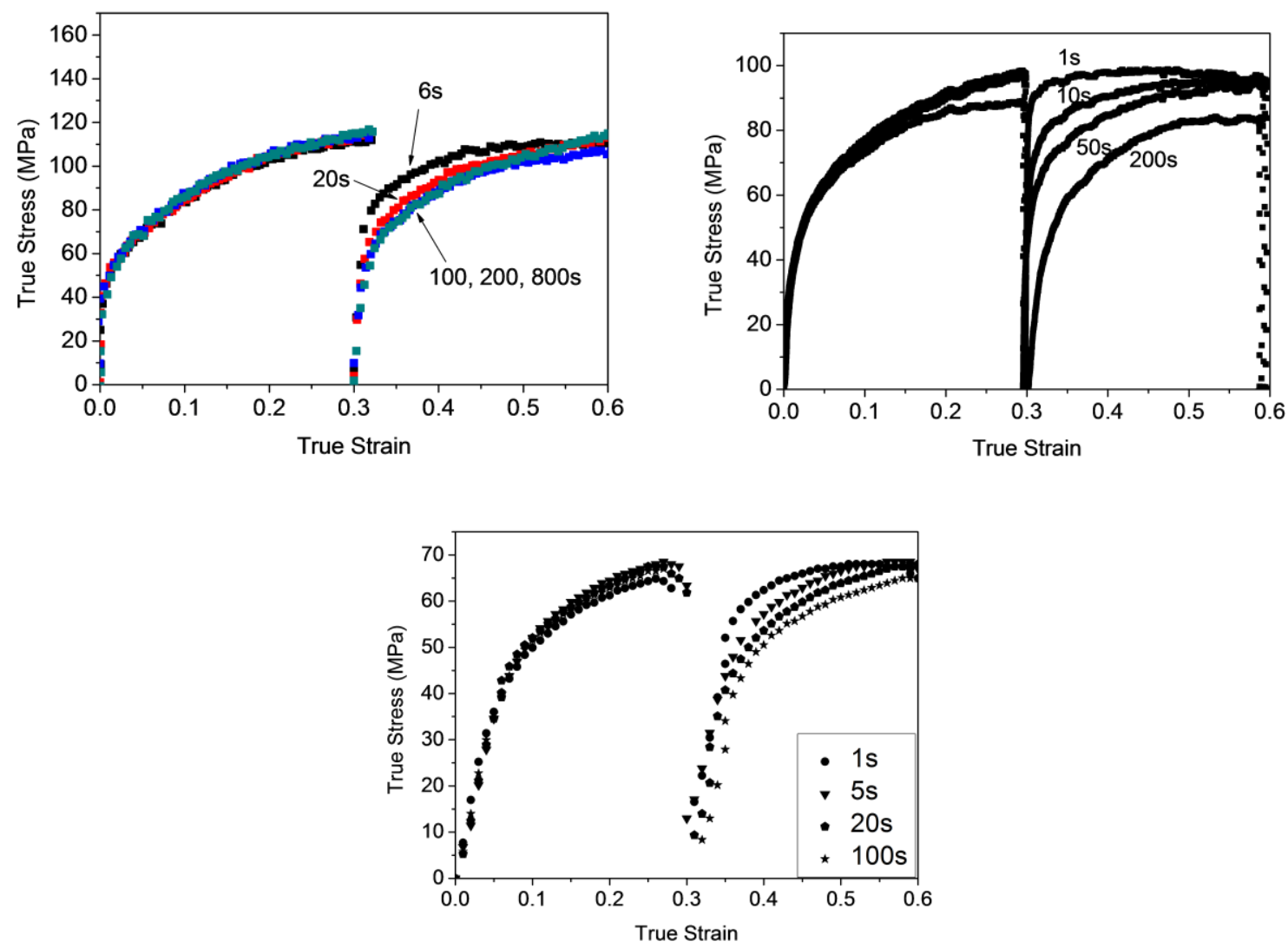

Figure 3. Stress-Strain curves for the Nb-Mo industrial steel, obtained from a double deformation test at $1000^{\circ} \mathrm{C}$, (a) uniaxial compression with MTS, $\varepsilon=0.3 \mathrm{~d} \varepsilon / \mathrm{dt}=0.05 / \mathrm{s}$, (b) uniaxial compression with dilatometer, $\varepsilon=0.3, \mathrm{~d} \varepsilon / \mathrm{dt}=0.05 / \mathrm{s}$, (c) torsion, $\varepsilon=0.3, \mathrm{~d} \varepsilon / \mathrm{dt}=1 / \mathrm{s}$.

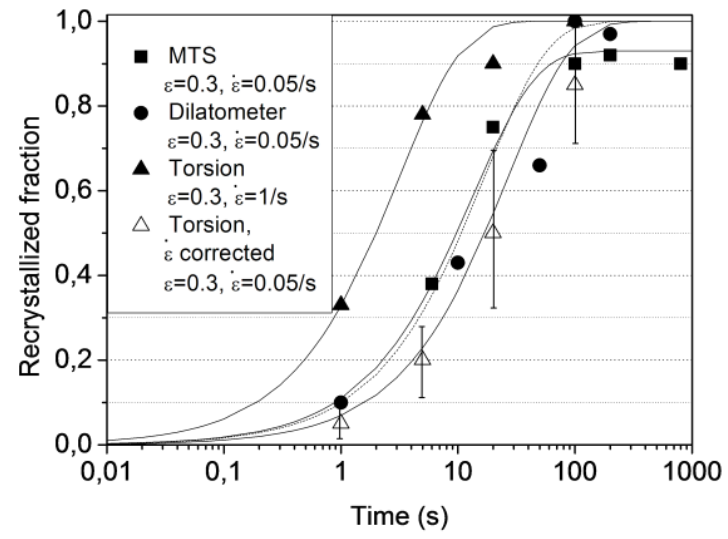

Figure 4. Recrystallized fraction versus time curves for the Nb-Mo industrial steel, obtained from the double deformation method, using three different simulation techniques. All samples were reheated at $1250^{\circ} \mathrm{C}$ for $300 \mathrm{~s}$ and subsequently deformed at $1000^{\circ} \mathrm{C}$. The fractions were obtained from Figure 3, using the $2 \%$ offset method. 

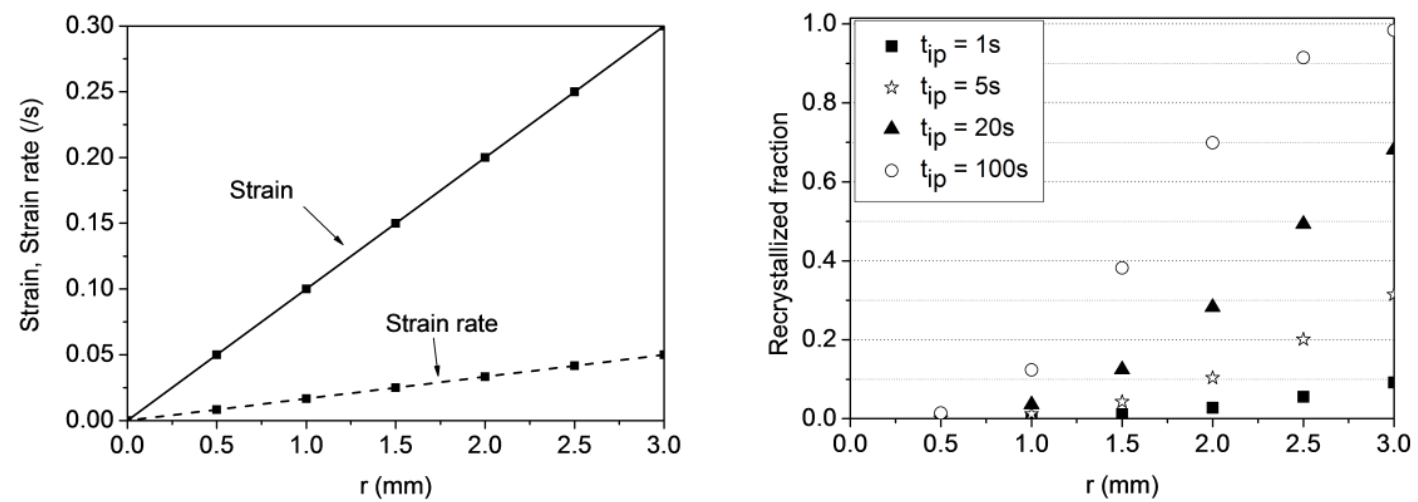

Figure 5. (a) Variation of the strain and the strain rate with the torsion sample diameter, (b) variation of the recrystallization kinetics with the sample diameter.
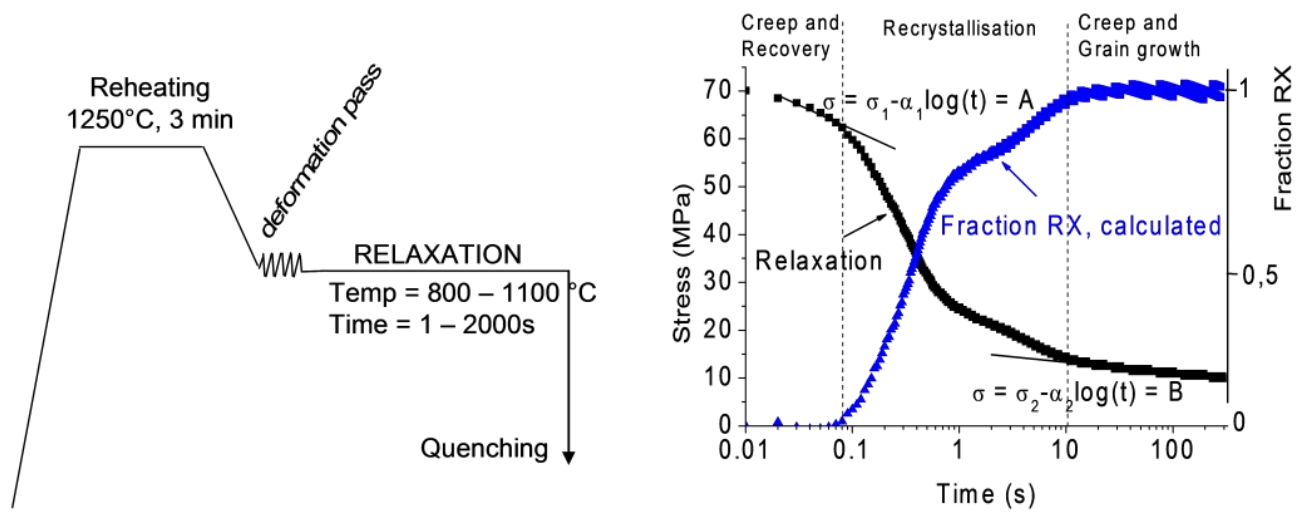

Figure 6. Illustration of the principle of a stress relaxation test (left) and illustration of the analysis of a stress relaxation test following the Karjalainen approach (right).
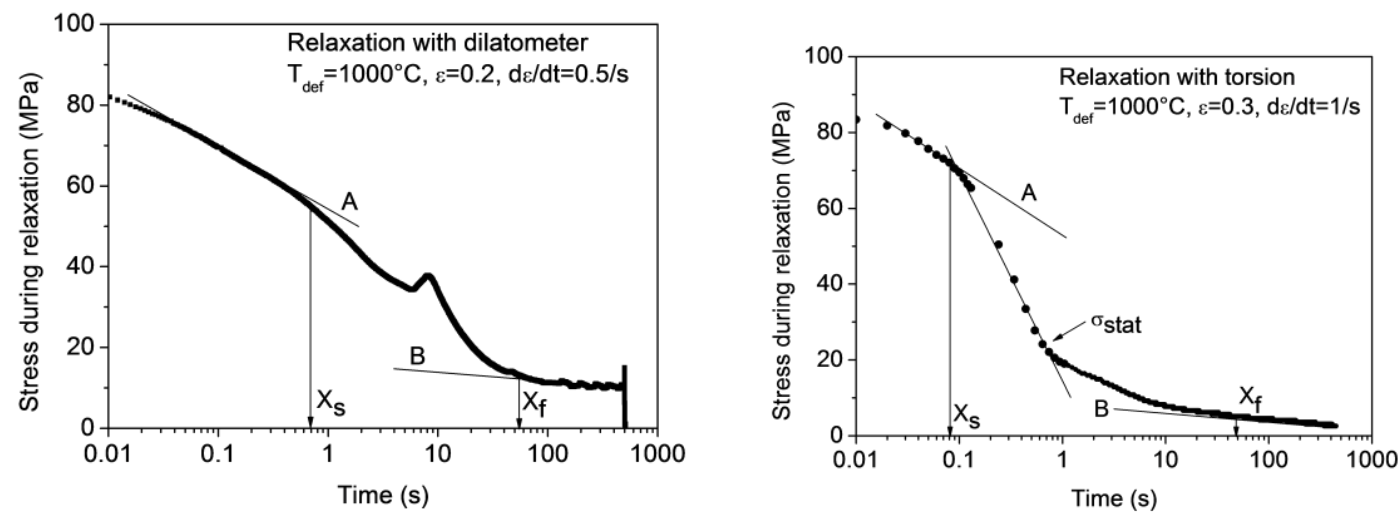

Figure 7. Stress relaxation of Nb-Mo alloy obtained from (a) torsion and (b) dilatometer in compression mode, using Karjalainen's approach. 


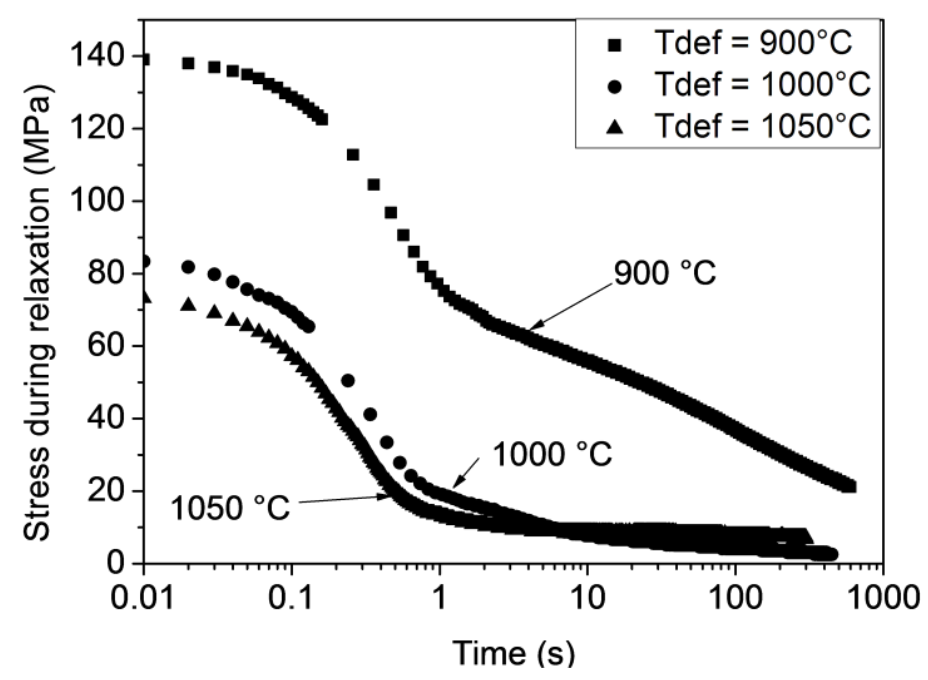

Figure 8. Stress relaxation curves of the Nb-Mo industrial alloy obtained from torsion tests (reheating $1250^{\circ} \mathrm{C}, \varepsilon=0.3, \dot{\varepsilon}=1 \mathrm{~s}^{-1}$ ) at different deformation and relaxation temperatures.

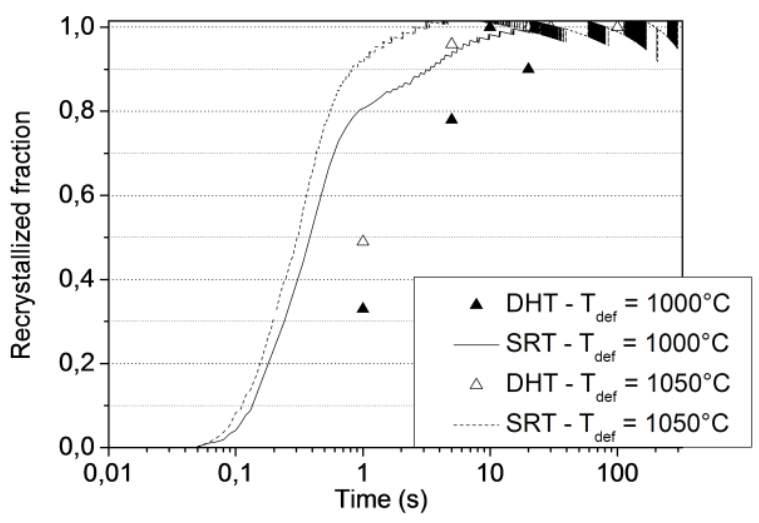

Figure 9. Comparison between the results from a double deformation test and a the stress relaxation test, both performed in torsion, on the Nb-Mo industrial steel (reheating $1250^{\circ} \mathrm{C}-300 \mathrm{~s}, \varepsilon=0.3, \dot{\varepsilon}=1 \mathrm{~s}^{-1}$ ).

\section{TABLES CAPTIONS}

Table I. Chemical composition of the alloys (in wt $\%$ unless stated otherwise)

\begin{tabular}{|l|c|c|c|c|c|c|c|}
\hline & $\mathrm{C}$ & $\mathrm{Mn}$ & $\mathrm{Si}$ & $\mathrm{Al}$ & $\mathrm{Nb}$ & $\mathrm{Ti}$ & $\mathrm{N}$ \\
\hline $\begin{array}{l}\text { C-Mn } \\
\text { reference }\end{array}$ & 0.02 & 1.5 & 0.26 & 0.043 & - & $\begin{array}{c}20 \\
\mathrm{ppm}\end{array}$ & $\begin{array}{c}18 \\
\mathrm{ppm}\end{array}$ \\
\hline $\mathrm{C}-\mathrm{Mn}-0.16 \mathrm{Nb}$ & 0.02 & 1.5 & 0.26 & 0.067 & 0.17 & $\begin{array}{c}80 \\
\mathrm{ppm}\end{array}$ & $\begin{array}{c}20 \\
\mathrm{ppm}\end{array}$ \\
\hline
\end{tabular}

